\title{
Ontem não te vi em Babilónia: territórios da memória, tempo de silêncio e solidão
}

Vera Lúcia Ramos de Azevedo Universidade Castelo Branco - RJ

\section{$p$}

erguntado sobre os títulos de seus romances, António Lobo Antunes responde: "Normalmente, os títulos só começam a aparecer a dois terços do livro. Não é nenhuma angústia porque sei sempre que ele vai aparecer, é apenas uma questão de tempo. O que é curioso é que, depois, sem que se dê conta, é o título para o livro."1

Ora, não é diferente em Ontem não te vi em Babilónia. Mais uma vez, pode aqui também o título dar a dimensão dos procedimentos autorais inerentes à sua ficção, assinalando ser o mesmo, sem dúvida, em se tratando de obra de Antunes, uma via preliminar para o enfrentamento de sua narrativa ficcional. Indo além da "função primeira do título", que "é a de referência", segundo Compagnon, em Antunes os títulos também nunca são "periféricos" em relação ao tecido romanesco, mas apontam "o texto em desenvolvimento, em processo", ${ }^{2}$ remetendo, assim, ao movimento dinâmico através do qual a narrativa é estruturada e antecipando os deslocamentos e os desvios que a caracterizam.

Do título - Ontem não te vi em Babilónia -, certamente, não se espera que o mesmo venha estabelecer vínculos ideativos

\footnotetext{
${ }^{1}$ ARNAUT, 2008, p. 533.

${ }^{2}$ COMPAGNON, 2007, p. 107.
} 
com as vozes narrativas que se alternam no romance, haja vista as marcas espaciais e/ou temporais contidas em seu enunciado não terem sustentação no que é buscado pelos narradores em seu passado. Deste modo, nem o ontem nem a mítica Babilónia podem ser tomados como manifestação discursiva do que os narradores pretendem resgatar pela memória. A busca do passado no romance, circunscrita a uma única madrugada, da meia-noite às cinco da manhã, e estendida a locais diversos, como Évora, Estremoz ou Lisboa, dentre outros, concorre tanto para o esvaziamento temporal do ontem quanto para a desreferencialização espacial da mítica Babilónia, mantida em suspenso pelo romance como espaço lacunar da memória dos personagens.

No entanto, se aí não se estabelecem correspondências no plano dos conteúdos, penso que o título, conforme explicado pela epígrafe - "em escrita cuneiforme num fragmento de argila, 3000 anos a.C." -, por assinalar práticas intertextuais comuns em Antunes, aqui, remetendo o romance a uma situação textual regressiva que com o mesmo dialoga, já prenuncia o campo das territorialidades a serem engendradas pelo romance, no que se refere à própria estratégia narrativa, marcada pelo percurso difuso dos relatos dos narradores na longa madrugada que têm diante de si.

Ana Emília, Alice e Osvaldo são as vozes que se alternam em cada segmento da narrativa, constituída de seis partes, correspondentes às horas da madrugada, dadas em sequência. $\mathrm{E}$, ainda que outras vozes sejam incorporadas a essa narrativa, as tensões que aí afloram são decorrentes preponderantemente dos relatos das histórias pessoais desses três personagens, contaminando, entretanto, os das demais vozes, o que faz que entre os mesmos se estabeleça um campo comum para as lembranças.

A busca do passado é o que move os relatos memorialistas dos personagens, reconstituição sempre penosa de um passado 
que oscila entre a possibilidade de seu resgate pela memória e a ocultação do mesmo pelo esquecimento. A narrativa, em seu movimento pendular, atesta as idas e vindas das lembranças, seus avanços e recuos, as oscilações entre o que pode emergir como revelação do passado e o que deste permanece como zona obscura e intransponível. O descontínuo da narrativa parece estar irremediavelmente ligado às trevas da noite, impedindo a memória de seguir seu curso, travando-a, desviando-a ou mesmo levando-a à exaustão, seja pelo movimento reiterativo da memória que não a deixa avançar, seja pelo movimento restritivo que a faz capitular, anulando-a pelo esquecimento.

Para Ana Emília, dentre outras lembranças que vêm à tona, são as lembranças da filha que se suicidou aos quinze anos, indo do "passado movediço por um instante fixo" ao "passado movediço sempre a alterar-se, a crescer", ${ }^{3}$ que lhe dão a medida da precariedade e/ou impossibilidade de sua busca; para Alice, é a precariedade de si, expressa pelo enunciado "Francamente não sei o que se passa comigo hoje" $\mathrm{e}^{4}$ ou então "Não sou uma pessoa interessante", ${ }^{5}$ que faz convergir as lembranças do passado aos seus cinquenta e seis anos, quase cinquenta e sete; para Osvaldo, é através das lembranças de Peniche e do preso a quem torturava, repetidas pelo refrão do médico da polícia "- É melhor não insistirem por hoje", 6 que o passado revela a insuportabilidade de sua memória no presente.

Os relatos, sem dúvida, pela gravidade do passado a que aludem, pressentem que, por mais que se empenhem na elucidação dos fatos pela memória, estão longe de atingir a

${ }^{3}$ LOBO ANTUNES, 2008, p. 332-333.

${ }^{4}$ LOBO ANTUNES, 2008, p. 39.

${ }^{5}$ LOBO ANTUNES, 2008, p. 105.

${ }^{6}$ LOBO ANTUNES, 2008, p. 27. 
recordação bem-sucedida, denominada por Ricoeur em $A$ memória, a história, o esquecimento como memória "feliz", 7 o que é agravado sobremaneira pelas condições vividas pelos personagens ao longo da madrugada, num misto de insônia, vazio ou torpor. Se não fosse pela impossibilidade mesma de uma recuperação plena da memória, a noite antuniana propicia a vulnerabilidade dos relatos e da memória e, consequentemente, a iminência do esquecimento.

Segundo Ricoeur,

Buscamos aquilo que tememos ter esquecido, provisoriamente ou para sempre, com base na experiência ordinária da recordação, sem que possamos decidir entre duas hipóteses a respeito da origem do esquecimento: trata-se de um apagamento definitivo dos rastros do que foi aprendido anteriormente, ou de um impedimento provisório, este mesmo eventualmente superável, oposto à sua reanimação?" ${ }^{\prime \prime}$

Penso que os relatos que compõem o romance de Antunes manifestam tanto o temor da memória quanto o temor do esquecimento. A lembrança da menina morta, a desesperança dos cinquenta e seis anos e o horror das sessões de tortura integram o quadro da memória que quer emergir e que deve ser motivo de indagação; ao mesmo tempo, porém, este quadro, por se instituir como o mais doloroso, trava a ação da memória e resvala para as formas do esquecer. Nem Ana Emília, nem Alice, nem Osvaldo podem responder à pergunta de Ricoeur sobre $o$ apagamento provisório ou definitivo de suas lembranças, pois, mesmo quando a memória elide em direção ao esquecimento, $\mathrm{o}$ processo se reinstaura e os relatos prosseguem noite adentro.

\footnotetext{
7 RICOEUR, 2007, p. 46.

${ }^{8}$ RICOEUR, 2007, p. 46.
} 
Esse movimento da memória, entre a tentativa de recuperação do passado e a constatação da inevitabilidade de seu apagamento, concorre para a natureza fragmentada da narrativa, que, através de depoimentos que ora se esclarecem, ora se confundem e muitas vezes se misturam, atesta o grau de dispersão dos relatos, de seus cortes abruptos ou de sua própria reiteração, levada à exaustão.

Em cada relato, para além das lembranças nucleares já destacadas, nos deparamos com outras que se ramificam e que se interrompem, retomadas mais adiante no processo reiterativo próprio da narrativa de Antunes.

Em relação a Ana Emília, além das lembranças da filha, seu relato se espraia pelas lembranças do pai e do homem que a visitava em Lisboa; em relação a Alice, além de seus cinquenta e seis anos, a azinheira, o hospital em que trabalhava como enfermeira e o marido; em relação a Osvaldo, além do preso a quem torturava, a mãe e a irmã em Estremoz. No entanto, a narrativa do romance não tece de maneira ordenada tais lembranças, uma vez que as mesmas não afetam apenas cada um desses personagens em particular. Por exemplo, a lembrança da menina morta aos quinze anos integra também a memória de Osvaldo, homem que visitava Ana Emília em Lisboa. Já a lembrança dos presos em Peniche é recorrente não só a Osvaldo, policial e torturador, como também a Alice, sua mulher, e a Ana Emília, com quem mantém um relacionamento, e cujo marido, "inimigo da Igreja e do Estado", é alvo de tortura por parte do próprio Osvaldo.

Tais lembranças, se, por um lado, afetam direta ou indiretamente dois ou mais personagens, por outro, afetam também a própria construção da narrativa, pelo caráter repetitivo dos enunciados, marcados por sua ocorrência difusa e lacunar, uma vez que o tartamudear das lembranças - comprometendo-se mutuamente ou elidindo-se umas às outras - pode pressupor a 
falta de confiabilidade na memória e, consequentemente, a imaginação como alternativa diante da memória não consumada e/ou fadada ao esquecimento.

Segundo Ricoeur,

Ser mais uma vez dado, não é ser apenas dado. A diferença não é mais contínua, mas descontínua. Surge, então, de forma temível, a questão de saber em que condições a "reprodução" é reprodução do passado. É da resposta a essa questão que depende a diferença entre imaginação e lembrança. É, pois, a dimensão posicional da relembrança que faz a diferença. ${ }^{9}$

Penso que a questão, conforme formulada por Ricoeur, possa alargar a compreensão tanto da memória quanto da narrativa propriamente dita. Isto porque, ao eleger a reiteração e os cortes como uma de suas estratégias narrativas, Antunes parece impedir que a memória se sustente como mera "reprodução" do passado, alicerçada em sua fixidez. Quando as lembranças vão e voltam, quando os relatos assumem ser a memória passível de um processo permanente de alteridade, manifestando sua diferença em relação ao já constituído, não é, pois, a mesma memória que volta, mas outra, potencializada pela imaginação e pelo escuro da noite e expressa pelo descontínuo da narrativa, esta, também dada como diferença, porque repetição de si mesma como outra. Pode-se pensar mesmo em um duplo descontínuo e, ampliando-se o enunciado ricoeuriano, passa-se a reconhecer no romance a "dimensão posicional" tanto da relembrança quanto da narrativa.

As lembranças, dadas mais uma vez, incessantemente, são e não são mais as mesmas, mas redimensionadas, dadas em diferença de si, como lembranças imaginadas, tanto como

${ }_{9}^{9}$ RICOEUR, 2007, p. 53. 
marca da insuficiência da memória quanto como embate contra o esquecimento. Os personagens, portanto, temendo a deterioração da memória do passado, aturdidos pela madrugada que cessará às cinco horas, fazem da escrita a via através da qual os relatos também estes trazidos mais uma vez - venham inscrever-se na temporalidade de uma outra noite, marcada igualmente pela escuridão da narrativa, agonizante pelo pressentimento de seu fim.

Essa premência da escrita, como forma de atravessar a madrugada e os desafios impostos pela memória, inscreve o romance de Antunes na chave de uma temporalidade indissoluvelmente atrelada aos relatos que aí se processam, se alternam e se imbricam, manifestando o traçado sinuoso e entrecortado de sua narrativa. Os personagens vivem uma agonia escritural, contingência na qual se situam durante o tempo de duração da madrugada, pois transpor as horas da insônia não se faz apenas por trazer à tona a memória - ou o esquecimento - do passado, mas por inscrevê-los como escrita, outorgando a si mesmos e aos seus relatos uma condição narrativa, como forma de suportarem o vazio e a escuridão.

Penso que a agonia escritural a que me referi possa ser acompanhada com base no Ricoeur de Tempo e narrativa, para quem "o tempo torna-se tempo humano na medida em que está articulado de modo narrativo; em compensação, a narrativa é significativa na medida em que esboça os traços da experiência temporal". ${ }^{10}$ Partindo da tese da reciprocidade entre o tempo agostiniano e a intriga aristotélica, deste modo explica Ricoeur sua escolha dos dois autores: se um "inquire sobre a natureza do tempo, sem aparentemente se preocupar em basear nesta investigação a estrutura narrativa", o outro "constrói sua teoria

${ }^{10}$ RICOEUR, 1994, p. 15.

${ }^{11}$ RICOEUR, 1994, p. 16. 
da intriga dramática sem consideração das implicações temporais de sua análise."11

Ora, no romance de Antunes, pode-se pensar na articulação proposta por Ricoeur, uma vez que os relatos devem conferir às lembranças do passado uma dimensão narrativa que venha situar os personagens no tempo, este, ainda que delimitado narrativamente pela exígua madrugada, com hora para acabar.

Vários são os enunciados proferidos pelos personagens ao longo do romance que atestam a urgência da escrita, seja através da nomeação desse espaço/tempo escritural como livro, romance ou vida, seja através da explicitação do ato de escrever como premência ou terminalidade. Estar ali, naquele espaço escritural, no entanto, é defrontar-se com temporalidades esquivas: seja a da memória do passado, por não viabilizar o reencontro dos personagens consigo mesmos; seja a da escrita no presente textual, por acenar-lhes com sua própria finitude.

O romance, ao problematizar as formas da temporalidade pretérita trazida ao presente pela memória, faz que a única possibilidade de inserção na temporalidade seja dada pelo presente da narrativa. Se a memória falha, se o esquecimento impõe seus limites às lembranças do passado, aos personagens só resta a madrugada como depositária da busca desenfreada de si mesmos e do que ficou para trás, narrativamente.

Essa passagem entre temporalidades - dos impedimentos da memória do passado à afirmação da escrita - pode ser aproximada à "atividade da configuração", conforme denominação de Ricoeur para explicar a transição entre os dois primeiros estágios da mimese, uma vez que "essa função de mediação deriva do caráter dinâmico da operação de configuração que nos faz preferir o termo da tessitura da intriga ao de intriga e o de disposição ao de sistema. Todos os conceitos relativos a esse nível designam, com efeito, operações."12

${ }^{12}$ RICOEUR, 1994, p. 104. 
No romance de Antunes, essa operação poderia ser depreendida da própria ação narrativa dos personagens, como forma de configurar narrativamente as lembranças trazidas pela memória e/ou elididas pelo esquecimento. Deste modo, passando do tempo vivido ao tempo narrado, os personagens tentam realizar, cada um a seu modo, a "tessitura da intriga", operação que, esclarece ainda Ricoeur, "extrai de uma simples sucessão uma configuração". ${ }^{13}$ As lembranças da ordem do vivido passam, assim, pela operação que vai inscrevê-las na ordem (ou desordem?) da narrativa.

A prática escritural dos personagens assume, então, as mais variadas formas: por parte de Alice, por exemplo, sua ação narrativa expressando suas próprias reservas quanto à consecução do processo de configuração em que se vê empenhada: "e como traduzir o que não consigo explicar"; ; o reconhecimento de sua ingerência no que se refere à passagem, conforme aludida por Ricoeur, da sucessão à configuração: "o que me cansa pôr as memórias em ordem, ter de contar isto tudo"; 15 já por parte de Osvaldo, em tom mais grave, a configuração narrativa sendo questionada quanto à operacionalização da mesma, haja vista a própria reversão do processo: "Não era nada do que escrevi até agora o que queria dizer" ${ }^{16}$

O romance, ao deixar entrever os impasses narrativos com os quais se deparam os personagens, procura ainda relacionar tais impasses à condição de esfacelamento dos sujeitos, cindidos por suas dores pessoais e coletivas.

${ }^{13}$ RICOEUR, 1994, p. 103.

${ }^{14}$ LOBO ANTUNES, 2008, p. 147.

${ }^{15}$ LOBO ANTUNES, 2008, p. 163.

${ }^{16}$ LOBO ANTUNES, 2008, p. 285. 
Por isso, Peniche, imagem recorrente no romance, talvez capitalize para si a referência de um dos lugares da dor na vivência dos personagens. Osvaldo, cuja vida está atrelada indissoluvelmente à função de policial e torturador, não tem como escapar dos efeitos de sua função na prisão, também ele torturado por si mesmo. Se, como torturador, sodomiza simbolicamente o preso, obrigando-o a usar vestido e brincos, como torturado, sob o efeito da violência nele introjetada, enfrenta a impossibilidade dos laços afetivos, tanto em sua relação com a mulher, Alice, quanto em sua relação com Ana Emília, mulher a quem visitava em Lisboa. Nos três personagens, as relações malogradas e o investimento afetivo imobilizado pelo ódio, pela indiferença ou pelo vazio.

Peniche, lugar de práticas políticas da ditadura salazarista, é absorvido pelo romance de Antunes, no entanto, para além da mera referencialização histórica. E, ainda que não se possa desconsiderar a afirmativa de Ricoeur de que tanto a narrativa histórica quanto a de ficção "dependam das mesmas operações configurantes", ${ }^{17}$ uma vez que a distinção entre os dois modos narrativos seja pautada tão somente pela questão da verdade, Peniche, como local historicamente dado como representação das dores coletivas na cena portuguesa, é configurado deste modo pelo romance, dentro da "mimética textual e literária", segundo expressão de Ricoeur, também como lugar emblemático do aprisionamento dos indivíduos por si mesmos, do aniquilamento total e da perda de qualquer sentido humano.

Os efeitos desse aniquilamento contaminam, sem dúvida, o processo escritural ao qual se lançam os personagens, fazendo que o processo de configuração da narrativa se veja permanentemente ameaçado e/ou prorrogado, desafio que lhes é imposto madrugada adentro.

${ }^{17}$ RICOEUR, 1995, p. 10. 
Na pergunta de Alice - "(duas horas da manhã e o que se pode fazer, como evitar que isto acabe?)"118 -, a inevitabilidade do fim da madrugada como marco de uma temporalidade narrativa não consumada; na dúvida de Ana Emília - "ignoro se alcançarei a manhã, são três horas e quantas manhãs me faltam, quantas horas" ${ }^{\prime 19}$-, a consecução da narrativa antecipada como falta e/ ou privação do tempo; no desabafo de Osvaldo - "quatro da manhã, santo Deus (...) nada do que escrevi até agora me serve $^{\prime 20}$-, a temporalidade esquiva e a constatação da ineficácia da configuração narrativa.

No entanto, ainda que os personagens pressintam a precariedade de sua ação narrativa e de sua inscrição no tempo, haja vista os entraves que enfrentam no processo de configuração, a tentativa de preenchimento desses vazios fica patente pelo recurso à interlocução, instância produtiva e dinâmica, pelo movimento relacional que aí se desencadeia.

Penso que a interlocução pode ser vinculada ao terceiro estágio da mimese, o da refiguração, que, explica Ricoeur, "marca a intersecção entre o mundo do texto e o mundo do ouvinte ou do leitor", ${ }^{21}$ pois o "ato de leitura articula-se com o dinamismo próprio do ato configurante, o prolonga e o conduz a seu termo".22

No romance, esse ato de leitura pode ser aproximado ao movimento de interação textual empreendido pelos personagens, considerando-se aqui a interlocução como forma de expansão tanto dos seus limites narrativos quanto de suas amarras no tempo.

${ }^{18}$ LOBO ANTUNES, 2008, p. 143.

${ }^{19}$ LOBO ANTUNES, 2008, p. 229.

${ }^{20}$ LOBO ANTUNES, 2008, p. 286.

${ }^{21}$ RICOEUR, 1994, p. 110.

${ }^{22}$ RICOEUR, 1994, p. 111. 
O mundo do ouvinte ou do leitor, deste modo, seria representado não só pelo leitor do romance, mas também por instâncias não nomeadas de recepção textual, com função de fazer desencadear o processo narrativo e/ou de torná-lo exequível.

Assim, no apelo de Ana Emília: "(não me empurrem para terminar o meu relato... $)$ "23 ou então "(estou a acabar, um momento, não me impeçam amigos) ${ }^{\prime \prime},{ }^{24}$ em que a interferência não nomeada no processo narrativo - "não me empurrem", "não me impeçam" - parece encobrir entraves no "mundo do texto", para usarmos a expressão de Ricoeur; nas conjecturas de Alice: "se me permitissem deixar de escrever" 25 ou "(irão ler o que escrevo") ?, ${ }^{26}$ em que a interlocução oscila entre uma função impeditiva subjacente e outra, alusiva à instância relacional produtiva; na revelação de Osvaldo: "Não tenho muito mais a acrescentar a não ser que vos odeio a todos. ${ }^{\prime 27}$ em que a repulsa à interlocução reitera a própria incompletude da ação narrativa.

Já no último capítulo, a interlocução se dá a manifestar através de duas situações narrativas que também parecem problematizar a relação entre o mundo do texto e o mundo do leitor, na acepção de Ricoeur.

"Escrevo o fim deste livro em nome da minha filha que não pode escrever" ${ }^{28}$ - é como começa o relato de Ana Emília. Ora, escrever em nome da filha é estabelecer uma interlocução forjada por outro modo de configuração da narrativa, já que a

${ }^{23}$ LOBO ANTUNES, 2008, p. 153.

${ }^{24}$ LOBO ANTUNES, 2008, p. 155.

${ }^{25}$ LOBO ANTUNES, 2008, p. 219.

${ }^{26}$ LOBO ANTUNES, 2008, p. 222.

${ }^{27}$ LOBO ANTUNES, 2008, p. 376.

${ }^{28}$ LOBO ANTUNES, 2008, p. 417. 
menina morta, ao assumir a narrativa, o faz a partir do estabelecimento de uma relação escritural com a mãe. Quem escreve na verdade? Ou melhor, a quem cabe a narrativa e sua configuração? A ambas, mãe e filha, ou a cada uma, em sua concomitância de funções, não excluída também a interlocução entre as mesmas?

O que não pensar também do seguinte enunciado, posto entre parênteses: "(chamo-me António Lobo Antunes, nasci em São Sebastião da Pedreira e ando a escrever um livro)" ${ }^{29}$ Não seria essa voz "autoral" (?) - pseudo ou intencional (?) também integrante desse movimento de interlocução entre o livro e sua escrita, o livro e sua leitura? Ou apenas mais uma tentativa fracassada?

Aqui, o romance de Antunes não estaria deixando entrever mais um desgaste, para além do já pressentido em relação à configuração narrativa? Não estaria também agora diante do impasse da "refiguração da experiência temporal", que, segundo Ricoeur, transporia "o limiar entre a configuração do tempo na narrativa e sua refiguração pela narrativa" ? ${ }^{30}$ Sendo assim, essas tentativas de interlocução sempre malogradas, conforme exemplos extraídos do romance, não atestariam de maneira definitiva os impedimentos do processo de refiguração, haja vista a desestabilização instaurada pelo romance entre a instância narrativa e o ato de leitura propriamente dito?

Penso que Ontem não te vi em Babilónia narra sua própria intransitividade. Ainda que as vozes se interpenetrem, que as dores sejam compartilhadas, os sujeitos que proferem os relatos veem-se imobilizados e impedidos de qualquer ação narrativa que os inscreva no tempo, para além de seu confinamento, por

${ }^{29}$ LOBO ANTUNES, 2008, p. 422.

${ }^{30}$ RICOEUR, 2010, p. 5. 
mais que os relatos transbordem a si mesmos e se constituam pelo descontínuo e pelo excesso.

Por fim, retomando o título do romance, talvez possamos terminar por onde começamos, pensando sobre a incomunicabilidade entre os sujeitos, já antecipada pelo enunciado - não te vi -, contido no título escolhido por Antunes. E, ainda que o autor afirme não fazer a menor ideia "de como é que aquele título se relaciona com aquelas personagens", ${ }^{31}$ somos tentados a pensar que o mesmo possa ser relacionado, sim, aos próprios personagens do romance que, em sua agonia escritural, na premência de se constituírem a si mesmos como sujeitos, narrativamente, percorrem insones aquela madrugada. A impossibilidade de um ver o outro se estende à impossibilidade de narrar e/ou de escrever o livro, uma vez que a narrativa se depara com o seu próprio aniquilamento, impedida tanto de trazer à tona a memória, quanto de perfazer o tríplice processo da mimese, conforme proposto por Ricoeur. Em Ontem não te vi em Babilónia - é como concluímos nossa resposta ao autor - o "não te vi" do título certamentejá prenuncia as vozes de personagens que tentam em vão romper a clausura da narrativa, debatendo-se agonicamente no vazio do tempo em que dura aquela madrugada de silêncio e solidão.

${ }^{31}$ ARNAUT, 2008, p. 533. 


\section{Referências}

ARNAUT, Ana Paula (Ed.). Entrevistas com António Lobo Antunes 1979-2007: confissões do trapeiro. Coimbra: Almedina, 2008.

COMPAGNON, Antoine. O trabalho da citação. Trad. Cleonice P. B. Mourão. Belo Horizonte: Editora UFMG, 2007.

LOBO ANTUNES, António. Ontem não te vi em Babilónia. Rio de Janeiro: Objetiva, 2008.

RICOEUR, Paul. A memória, a história, o esquecimento. Trad. Alain François [et al.]. Campinas: Ed. da UNICAMP, 2007.

RICOEUR, Paul. Tempo e narrativa (tomo 1). Trad. Constança Marcondes Cesar. Campinas: Papirus, 1994.

RICOEUR, Paul. Tempo e narrativa (tomo 2). Trad. Marina Appenzeller; revisão técnica Maria da Penha Villela-Petit. Campinas: Papirus, 1995.

RICOEUR, Paul. Tempo e narrativa (tomo 3). Trad. Claudia Berliner; revisão da trad. Márcia Valéria Martinez de Aguiar. São Paulo: Ed. WMF Martins Fontes, 2010. 


\section{Resumo}

$\mathrm{O}$ artigo pretende analisar o romance Ontem não te vi em Babilónia, de António Lobo Antunes, centrando a reflexão nos aspectos relacionados às estratégias narrativas empregadas pelo autor. Inicialmente, o caráter descontínuo e fragmentado dos relatos dos narradores será acompanhado através da oscilação entre memória e esquecimento. Em seguida, também com base em Ricoeur, a análise procurará investigar o processo de configuração e de refiguração da narrativa empreendido pelos narradores, em sua tentativa, ainda que precária ou mesmo fracassada, de estabelecer, através de sua ação narrativa, uma vivência no tempo.

\section{Résumé}

Cet article se propose d'analyser le roman Ontem não te vi em Babilónia, écrit par António Lobo Antunes, en posant la réflexion sur les aspects relatives aux stratégies narratives employées par l'auteur. D'abord, on essaye d'y observer le parcours discontinu et fragmenté des rapports, à travers l'oscillation entre la mémoire et l'oublie. Ensuite, encore d'après Ricoeur, on y tourne vers le processus de configuration et de refiguration de la narrative produite par les narrateurs, si on y considere leur tentative d'obtenir, à cause de cette action, une expérience dans le temps, même qu'incertaine ou déchirée. 